\title{
ANÁLISE QUALITATIVA DOS TEXTOS DE CORREÇÕES DE ERRO DE UM ERP E DISTRIBUIÇÃO AUTOMÁTICA DAS TAREFAS
}

\author{
Wender de Oliveira Silva ${ }^{1}$, Willian Santos Silva ${ }^{2}$ e Aniel S. Morais ${ }^{3}$ \\ Faculdade de Engenharia Elétrica Universidade Federal de Uberlândia, Brasil. \\ 1'wender4j@gmail.com, 2williansantosptc@gmail.com, 3aniel@eletrica.ufu.br
}

\begin{abstract}
Resumo. Um sistema integrado de gestão ou ERP (Enterprise Resource Plain) é um pacote de software de negócio que compreende a gestão de várias áreas de uma empresa, centralizado em uma única base de dados. A construção de um software tão versátil requer equipes multidisciplinares respectivamente responsáveis por cada módulo do ERP. Este trabalho abordará o fluxo de tarefas no processo de manutenção de um sistema de gestão integrado de grande porte, tendo por objetivo, viabilizar e minimizar os erros no processo de classificação destas tarefas, propondo que a interpretação dos textos seja feita por um algoritmo em detrimento à interpretação dos funcionários inerentes ao processo de manutenção do ERP. Foram analisados os algoritmos "Support Vector Classifier; "Multinomial Naive Bayes" e a implementação de uma rede neural Perceptron para interpretar as tarefas e distribuí-las entre as equipes. Detalhamos o processo de preparação dos dados e a definição do algoritmo mais efetivo para a solução.
\end{abstract}

Palavras-chave: Inteligência Artificial; Análise Qualitativa; Classificação de Texto.

\section{QUALITATIVE ANALYSIS OF ERP ERROR CORRECTION TEXTS AND AUTOMATIC TASK DISTRIBUTION}

\begin{abstract}
An integrated management system or ERP (Enterprise Resource Plain) is a business software package which comprises the management of several areas of a company, centralized in a single database. The development of such versatile software requires multidisciplinary teams respectively responsible for each ERP module. This paper will address the flow of tasks in the process of maintaining an integrated management system for large scale, with the objective of making possible and minimizing errors in the classification process of these tasks, proposing that the interpretation of the texts be done by an algorithm in detriment to the interpretation of the employees inherent to the ERP maintenance process. The "Support Vector Classifier" algorithms were analyzed; "Multinomial Naive Bayes" and the implementation a Perceptron neuronal network to interpret tasks and distribute them among teams. We detail the data preparation process and the definition of the most effective algorithm for the solution.
\end{abstract}

Keywords: Artificial Intelligence; Text Classification; Qualitative Analysis.

\section{INTRODUÇÃO}

Um ERP (Enterprise Resource Plain) ou sistema integrado de gestão é um pacote de software de negócios que permite uma empresa integrar a maioria de seus processos, compartilhar dados, práticas comuns e acessar informações em um ambiente de tempo real, tal conceito advem da necessidade de melhoria nos processos e evolução de sistemas existentes não integrados. OS ERP's estabelecidos no mercado atendem segmentos tais como atacado, varejo, setor imobiliário, indústrias em geral e prestadores de serviços. Para atender tais segmentos é necessário a cobertura de processos triviais como controle de estoque, compra, venda, armazenagem, transporte, roteirização, contabilidade, folha de 
pagamento, controle de produção, projetos e prestação de serviço, entre outras, além de rotinas preditivas.

O ERP integra informações e elimina interfaces complexas entre sistemas não projetados para conversarem entre si, desta forma todos os processos de uma organização são colocados dentro de um mesmo sistema e de um mesmo ambiente (Harmon, Rosemann, \& Davenport, 2019).

A sustentação de um sistema integrado de gestão demanda uma estrutura adequada para atendimento do SLA (Service Level Agreement) com o cliente. As boas praticas da engenharia de software apontam para um conjunto de processos fluídos e consequentemente ferramentas que controlem 0 processo, a classificação e a responsabilidade das tarefas inerentes ao ERP. Como prática de mercado, o controle dos "bugs" (erros de sistema) são abstraídos por software denominados "Bug Tracking Systems" (BTS) que possibilitam reportar, rotular e acompanhar o processo de correção de um erro. 0 foco deste trabalho é viabilizar e minimizar os erros no processo de classificação destas tarefas, otimizando o fluxo do processo de correção e propondo que a interpretação dos textos seja feita por um algoritmo em detrimento à interpretação dos funcionários inerentes ao processo de manutenção do ERP.

\section{TRABALHOS RELACIONADOS}

Herzig, Just e Zeller (2013) ressaltaram a importância de classificar automaticamente as tarefas e como os erros de classificação impactam na predição de um erro. No trabalho foram analisados cinco projetos de código aberto gerenciados por dois BTS distintos e encontraram $33,8 \%$ de erros no processo de classificação.

Anvik, Hiew e Murphy (2006) implementou uma solução semi automatizada para classificar erros e definir um conjunto pequeno dos possíveis profisionais capazes de corrigir o problema. Comparou o algoritmo de decisão de árvore C4.5, Naive Bayes e SVC, optando pelo Support Vector Classifier e conseguindo resultados acima dos 50\%, alcançando até $64 \%$.

\section{COLETA, PREPARAÇÃO E ASPECTOS INERENTES AOS DADOS}

A motivação deste trabalho consiste no processo de sustentação de um ERP de grande porte que demanda a força de trabalho de mais de duzentos profissionais. Estas pessoas 
estão alocadas em sete macro equipes, cada qual especializada em determinados módulos ou conjunto de funcionalidades do sistema. Esta divisão é necessária a âmbito do domínio das regras de negócios, dada a versatilidade e nível de customização do ERP.

Neste cenário há um esforço humano na interpretação de problemas desde o atendimento feitos pelo setor de suporte até a definição da equipe de programadores responsável por retificar o bug reportado. Este problema é tipificado como de classificação, e, considerando que temos uma base de produção com 9.875 erros classificados entre as equipes, a solução é totalmente aderente a um algoritmo de classificação com abordagem de aprendizado supervisionado, dada as características do problema e a definição de uma base de dados com o aprendizado (Johnston \& Mathur, 2019). A figura 1 exibe a distribuição quantitativa entre células das ordens de serviços já classificadas.

A criação de uma tarefa de correção de erro existente no ERP é normalmente definida pela equipe de suporte que através das informações do usuário e do sistema (logs) tentam determinar e classificar a equipe responsável por retificar o problema. Confirmada a existência do bug, será necessário determinar a equipe que o irá resolver. Este fluxo onera trabalho interpretativo de pessoas e é comum que a tarefa seja enfileira para uma equipe que não é de fato a responsável pela correção do problema. A proposta deste trabalho é processar as informações textuais e efetuar a classificação das tarefas em detrimento ao esforço manual.

O preparo dos dados textuais tem por estratégia a construção de um conjunto representativo de palavras (bag of words), seguindo esta abordagem, removemos as stop-words que na prática são artigos, preposições e palavras de ligações e stemming que consiste em manter apenas os radicais das palavras (Passalis \& Tefas, 2018).

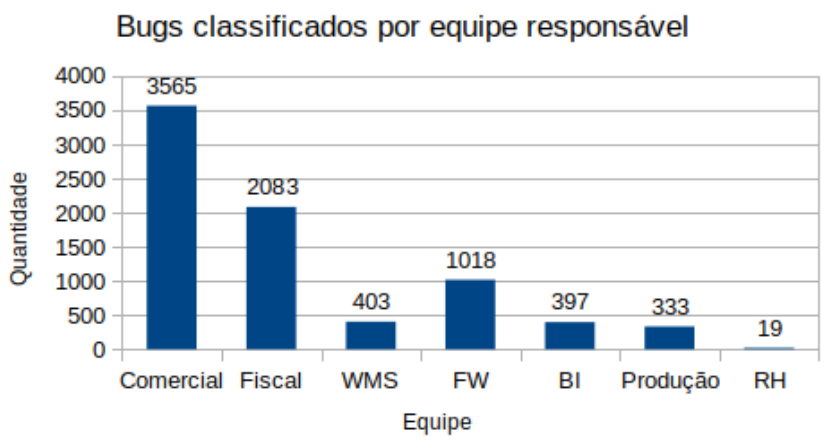

Figura 1. Composição da base de dados. 


\section{ALGORITMOS ABORDADOS}

O objetivo deste trabalho é viabilizar e minimizar os erros no processo de classificação de bugs, propondo que a interpretação dos textos seja feita por um algoritmo em detrimento à interpretação dos funcionários inerentes ao processo de manutenção do ERP. Três algoritmos foram avaliados: Multinomial Naive Bayes (MNB), Rede Neural Perceptron (Multicamadas) e Support Vector Classifier (SVC) com kernel linear.

Naive Bayes é um algoritmo de aprendizado supervisionado baseado na aplicação do Teorema de Bayes, possui abordagem estatística e assume que todos os atributos são independentes do contexto da classe (Gopal, 2019).

Redes Neurais artificiais (RNA) são modelos computacionais inspirados na forma como o cérebro processa informações. Em uma RNA o conhecimento também é adquirido e armazenado através das forças de conexão entre neurônios, também conhecidos como pesos sinápticos. Dentre as principais propriedades de uma RNA está a capacidade de lidar com problemas não lineares, adaptabilidade, informação contextual e capacidade de generalizar problemas, sendo tolerância a falhas e desvios (Patan, 2019).

Support Vector Classifier é uma técnica de aprendizado que baseia-se na construção de um hiperplano ótimo, de modo que ele possa separar diferentes classes de dados com a maior margem possível. A máquina de vetor de suporte é uma implementação do método de minimização estrutural de risco e fornece um bom desempenho de generalização em problemas de classificação de padrões, apesar de não incorporar conhecimento do domnínio do problema. Este atributo é único das máquinas de vetores de suporte (Gopal, 2019).

A escolha dos algoritmos MNB e SVC foi fundamentada na pesquisa dos trabalhos relacionados e a proposta da rede neural foi definida com base nas características do algoritmo e na capacidade de implementação de uma solução customizada e adpatável. Todos três algoritmos são de aprenziado supervisionado, logo, possuem a capcacidade de abstair as características da base de aprendizado e classificar as novas ocorrências segundo estas características (Johnston \& Mathur, 2019). 


\section{INVESTIGAÇÃO QUALITATIVA DOS DADOS}

O esforço despendido na construção e refinamento dos algoritmos teve resultado estabilizado em níveis não aceitáveis. Decidimos focar no teor dos dados e pautamos nossa análise conforme requisitos propostos por (Mills, 2018). Desta maneira, recorremos ao conhecimento de especialistas, endereçamos aspectos mais significativos, incluímos as maiores interpretações rivais e toda análise foi baseada em todas as evidências relevantes. O conhecimento dos especialistas das áreas foi fundamental para a comprensão do problema a ser resolvido, bem como características dos processos

No processo de refinamento dos dados, conseguimos identificar e eliminar padrões de textos que traziam vício ao conteúdo tais quais como: todos nomes de profissionais, modelos de textos utilizados por algumas áreas, nomes de setores que foram alterados. Montamos uma base de dados com 2312 termos retirados dos cadastros da empresa (banco de dados); documentos dos processos das áreas envolvidas, bem como dos especialistas de cada área da empresa como mencionamos. Na figura 2, como exemplo, demonstra as características textuais das tarefas da equipe $\mathrm{BI}$ (Business Intelligence), cuja as palavras em envidência seriam outras e termiam muito mais similaridade com outras equipes se não fosse este processo de análise. A melhoria nos resultados gerados por este processo será clarificada no capítulo seguinte.

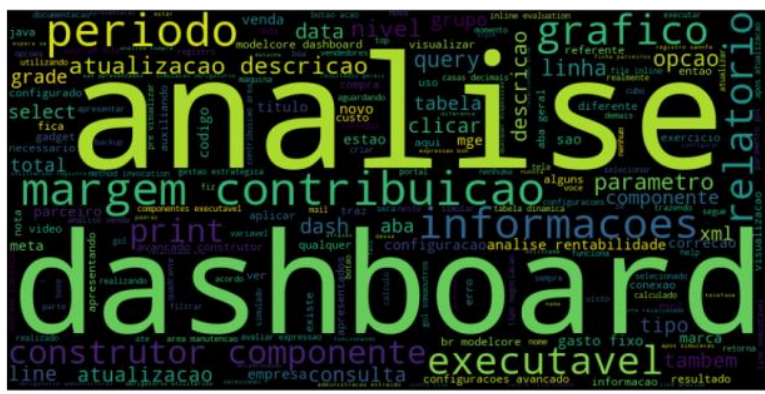

Figura 2. Nuvem de palavras da equipe BI

\section{LIÇÕES APRENDIDAS}

O Dentre as 9.875 amostras, separamos aleatoriamente 15\% para treino e $85 \%$ para teste, aplicamos

cada um dos algoritmos e confrontamos o resultado obtido. Este processo foi repetido 5.000 vezes e fizemos média da acuracidade de cada um dos três algoritmos. 
O algoritmo que demonstrou melhor performance foi o Support Vector Classifier com núcleo linear,

seguido por Multinomial Naïve Bayes e pela rede neural Perceptron. Os detalhes podem ser visto na tabela 1. Devemos considerar o resultado constante nas diversas baterias em que dividimos aleatoriamente a base de dados em treino e teste, respectivamente $85 \%$ e $15 \%$, obtivemos a média de $74,63 \%$.

A melhoria dos resultados através da preparação das informações, conforme podemos comparar nas

duas colunas da tabela 1, mostrou que o esforço na sofisticação do algoritmo teve retorno menor do que a análise de característica e sanitização dos textos. A implementação da rede neural artificial assim como o uso do kernel RBF no algoritmo SVC mostraram-se ineficientes, dando entendimento que o problema é de complexidade linear.

Tabela 1. Resultados dos algoritmos.

\begin{tabular}{lll}
\hline Algoritmo & Acuracidade texto puro & $\begin{array}{l}\text { Acuracidadetexto } \\
\text { processado }\end{array}$ \\
\hline SVC (linear) & $49.40 \%$ & $74.63 \%$ \\
Multinomial NB & $41.33 \%$ & $68.11 \%$ \\
RNA Perceptron & $32.91 \%$ & $53.42 \%$ \\
\hline
\end{tabular}

\section{CONSIDERAÇÕES FINAIS}

As técnicas para classificação de texto como propósito de automatização ou mineração de dados tem

sido amplamente utilizadas a fim de melhorar performance e custo de processos. Neste caso de estudo, analisamos o fluxo de tarefas no processo de manutenção de um ERP, tendo por objetivo minimizar os erros de classificação em detrimento ao processo manual.

Pautamos a solução inicialmente na busca de um algoritmo aderente ao problema, mas conforme ressaltamos nas lições aprendidas, o maior ganho de acuracidade foi na compreensão das característica do texto. Detalhamos o processo de coleta e processamento do texto na seção 3 Concluímos que os níveis de assertividade da funcionalidade aqui apresentada não permitem uma 
substituição completa na tarefa humana de classificação de ordens de serviço, mas podemos afirmar que como ferramenta preditiva há um ganho significativo diretamente proporcional aos $74,63 \%$ alcançados como média. Vale ressaltar que embora não existam dados a respeito da reclassificação que uma OS sofre, obtivemos em campo a informação que a tarefa humana não garante $100 \%$ de acuracidade.

\section{REFERÊNCIAS}

Anvik, J., Hiew, L., \& Murphy, G. C. (2006). Who should fix this bug? Proceeding of the 28th International Conference on Software Engineering - ICSE 06. doi: 10.1145/1134285.1134336

Gopal, M. (2019). Applied machine learning. New York: McGraw-Hill Education.

Harmon, P. (2019). Business process change: a business process management guide for managers and process professionals. Morgan Kaufmann.

Herzig, K., Just, S., \& Zeller, A. (2013). It's not a bug, it's a feature: How misclassification impacts bug prediction. 2013 35th International Conference on Software Engineering (ICSE). doi: 10.1109/icse.2013.6606585

Johnston, B., \& Mathur, I. (2019). Applied supervised learning with Python: use scikit-learn to build predictive models from real-world datasets and prepare yourself for the future of machine learning. Birmingham: Packt Publishing.

Mills, K. A. (2018). What are the threats and potentials of big data for qualitative research?. Qualitative Research, 18(6), 591-603.

Passalis, N., \& Tefas, A. (2018). Learning bag-of-embedded-words representations for textual information retrieval. Pattern Recognition, 81, 254-267.

Patan, K. (2019). Robust and Fault-Tolerant Control: Neural-Network-Based Solutions. Springer. 